\title{
A clinical study of preoperative carbohydrate administration to improve insulin resistance in patients with multiple injuries
}

\author{
Lei Qi", Yao Wu", Linli Shan, Yansong Dong, Guomin Mao, Guiwen Liang, Hui Gong, Cheng Xu, \\ Haiyan Jiang, Zhongwei Huang
}

Department of Emergency Medicine, Affiliated Hospital of Nantong University, Nantong, China

Contributions: (I) Conception and design: H Jiang, Z Huang; (II) Administrative support: H Gong, C Xu; (III) Provision of study materials or patients: L Qi, Y Dong; (IV) Collection and assembly of data: L Shan, Y Wu; (V) Data analysis and interpretation: G Mao, G Liang; (VI) Manuscript writing: All authors; (VII) Final approval of manuscript: All authors.

\#These authors contributed equally to this work.

Correspondence to: Haiyan Jiang; Prof. Zhongwei Huang. 20 West Temple Road, Department of Emergency Medicine, Affiliated Hospital of Nantong University, Nantong 226001, China. Email: jhy@ntu.edu.cn; tdfyhuangzw@163.com.

\begin{abstract}
Background: The purpose of this study was to investigate the tolerance and safety of carbohydrate administration to patients with multiple injuries prior to surgery, and to analyze the effects of carbohydrate intake on their immediate insulin resistance (IR), postoperative complications, and length of hospital stay.

Methods: A total of 125 patients with mild multiple injuries who were admitted to the Emergency Surgery Department of Affiliated Hospital of Nantong University for elective surgery were randomized to administration of either placebo or carbohydrate. Finally, 82 patients (male: 39, female: 43) successfully completed the experiment and collected data. Preoperative general condition, subjective comfort, blood glucose concentration, serum insulin and insulin resistance index (IR) were studied.

Results: The two groups of patients matched in gender, age, body mass index (BMI) $(\mathrm{P}>0.05)$. Patients in $\mathrm{CHO}$ group treated with carbohydrates three hours before surgery compared with patients treated with preoperative specification. The thirst, hunger and anxiety of the patients in the CHO group were significantly relieved $(\mathrm{P}<0.05)$. Blood glucose concentration, serum insulin, and IR were much lower in the CHO group $(\mathrm{P}<0.05)$.

Conclusions: It is a relatively safe approach that patients took carbohydrates 3 hours before surgery, and there was no statistically significant difference in the incidence of postoperative aspiration. Taking carbohydrates before surgery can not only relieve preoperative discomfort, but also reduce postoperative insulin resistance, which is helpful to avoid postoperative metabolic disorder and speed up recovery.
\end{abstract}

Keywords: Multiple injuries; carbohydrates; insulin resistance (IR); rapid recovery

Submitted Jun 19, 2020. Accepted for publication Aug 25, 2020.

doi: 10.21037/apm-20-1424

View this article at: http://dx.doi.org/10.21037/apm-20-1424

\section{Introduction}

Patients clinically present with insulin resistance (IR) for many reasons. IR is characterized by the destruction of glucose transporter 2 (GLUT2) and glucose transporter 4 (GLUT4) in muscle and adipose tissue under stressed states, such as trauma, infection, and surgery (1). Decreased sensitivity of peripheral tissue to insulin reduces its effect on the body, compared with the effect produced by normal physiological levels (2), and in turn reduces the body's glucose use. To maintain relative blood glucose stability, excessive insulin is secreted in compensation, leading to hyperinsulinemia. In recent years, it has been found that IR is related to the postoperative development of type 2 diabetes mellitus. This may be related to pre-surgery fasting and the stressed state of tissues post-surgery. IR is also 
related to trauma, inflammation, hormones, and intestinal flora, among other factors.

Surgery is often accompanied by anesthesia. A series of functional changes occur during anesthesia, including the relaxation of gastrointestinal sphincters, the weakening of gastrointestinal peristalsis, airway obstruction, and the weakening of the pharyngeal reflex. These changes frequently produce vomiting and aspiration during surgery.

Aspiration is a serious surgical complication that was initially thought to be related to anesthesia and the failure to correctly fast pre-surgery. It is characterized by immune inflammation, direct lung injury, and fibrous hyperplasia. Symptoms of aspiration include acute airway obstruction, aspiration atelectasis, Mendelson's syndrome, and aspiration pneumonia. As such, a sizeable amount of research has explored methods to reduce the incidence of aspiration.

In 1946, Mendelson proposed routine fasting for 812 hours before surgery. Up to now, however, most elective surgery in China has involved fasting for only 4 hours prior to surgery. Recent studies have focused on reducing aspiration risk in the perioperative period, particularly after general anesthesia. These studies have investigated surgical positioning, different medications, the use of ultrasound technology, and the use of gastric tubing.

In a further study, it was considered as high-risk factors that aspiration pneumonia was associated with, defining a gastric juice volume of $25 \mathrm{~mL}$ and a $\mathrm{pH}$ of 2.5 pre-surgery. Ingesting water dilutes gastric juice concentration, which reduces the degree of chemical damage to the lungs after aspiration. Theoretically, therefore, it is feasible to prevent the serious consequence of aspiration by reducing the presurgery fasting time. The amount and timing of liquid ingested that can dilute gastric juices and increase the rate of gastric emptying are vital in reducing the incidence of aspiration.

Early in the $21^{\text {st }}$ century, a Danish surgeon named Klaette described the term fast-track surgery (FTS). This involves promoting rehabilitation in surgical patients and aims to reduce stress damage in these patients to accelerate their recovery (3). Søreide et al. found that patients who followed a traditional fasting schedule pre-surgery had a gastric juice volume of $19-22 \mathrm{~mL}$ and a stomach $\mathrm{pH}$ of $1.9-2.0$, and patients who ingested $400 \mathrm{~mL}$ of water 2 hours prior to surgery had a gastric juice volume of $17-20 \mathrm{~mL}$ and a $\mathrm{pH}$ of 1.9. This indicates that the volume of fluid and $\mathrm{pH}$ in the stomach are primarily determined by stomach secretions (4). Nygren et al. found in the 1990s that the administration of preoperative carbohydrates could improve postoperative IR more effectively than ordinary liquids (5). Onalan et al. showed that preoperative oral carbohydrates improved postoperative IR of patients receiving laparoscopic cholecystectomy (LC) (6).

The purpose of the present study was to improve and standardize the use of preoperative oral carbohydrates in patients with surgery.

We present the following article in accordance with the CONSORT reporting checklist (available at http://dx.doi. org/10.21037/apm-20-1424).

\section{Methods}

\section{Participants}

One hundred and twenty-five patients with multiple injuries that presented to the Emergency Surgery Department of the Affiliated Hospital of Nantong University between August, 2019, and February, 2020, were selected for this study. Of these 125 patients, 82 (39 males and 43 females) completed the trial and produced evaluable data. Participants' ages ranged from $25-75$ years old. The inclusion criteria were as follows: an injury severity score no greater than 16 and a body mass index (BMI) of $18.5-23.9 \mathrm{~kg} / \mathrm{m}^{2}$.

The study was conducted in accordance with the Declaration of Helsinki (as revised in 2013), and has been approved by the Ethics Committee of the Affiliated Hospital of Nantong University (Approval number: 2019L002), and all the subjects and their families signed the informed consent documents.

\section{Randomization}

The patients were randomly divided into two groups, the carbohydrate group (CHO group) and the noncarbohydrate group (non-CHO group). Patients in the CHO group ( $\mathrm{n}=51$ ) were given $400 \mathrm{~mL}$ of oral carbohydrate after fasting for 12 hours and not ingesting fluids for 4 hours prior to surgery. Patients in the non-CHO group $(\mathrm{n}=50)$ fasted for 12 hours prior to surgery. All patients were operated on by the same surgeon and surgical team. The anesthesia received was the same across the two groups. The operative sites of the patients with multiple injuries were recorded. There was no significant difference between the two groups in intraoperative aspiration reflux, time of operation, intraoperative bleeding volume, and intraoperative fluid replacement volume (Table 1). 
Table 1 Intraoperative index

\begin{tabular}{lccc}
\hline Variables & Time of operation $(\mathrm{h})$ & Intraoperative bleeding volume $(\mathrm{mL})$ & Intraoperative fluid replacement $(\mathrm{mL})$ \\
\hline CHO group & $1.16 \pm 0.76$ & $304.87 \pm 97.34$ & $2,099.02 \pm 258.18$ \\
Non-CHO group & $1.08 \pm 0.59$ & $320.73 \pm 98.72$ & $2,075.60 \pm 243.18$ \\
$\mathrm{t} / \mathrm{x}^{2}$ & 0.491 & -0.732 & 0.423 \\
$\mathrm{P}$ value & 0.967 & 0.466 & 0.674 \\
\hline
\end{tabular}
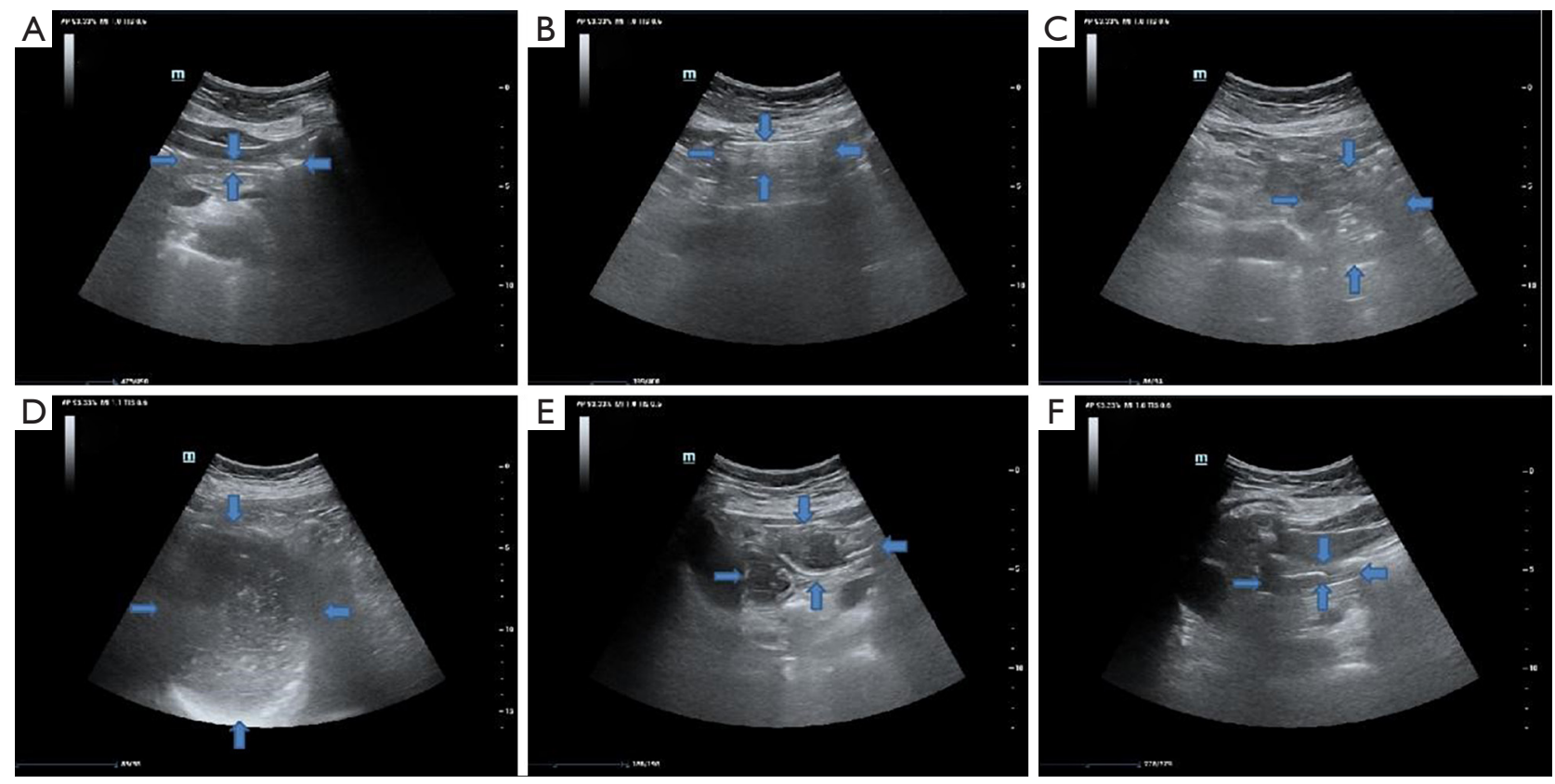

Figure 1 Ultrasound images. (A) No gastric content was present 3 hours prior to surgery. (B) The stomach began to fill when carbohydrate ingestion began. (C) After $200 \mathrm{~mL}$ of carbohydrate had been ingested, the gastric cavity was fuller. (D) After ingestion of $400 \mathrm{~mL}$ of carbohydrate the gastric cavity was filled. (E) The gastric cavity was half full by $20 \pm 8.5$ minutes after completing carbohydrate ingestion. (F) No gastric content was present $45 \pm 9.6$ minutes after completing carbohydrate ingestion.

\section{Color Doppler ultrasound}

Patients in the CHO group received $400 \mathrm{~mL}$ of carbohydrate solution orally 3 hours prior to surgery; ingestion was complete by 2 hours prior to surgery. Patients should not finish drinking carbohydrates for more than 20 minutes. Color Doppler ultrasounds were taken at patients' bedsides to monitor gastric filling and emptying in real time (Figure 1).

\section{Date collection}

A visual analog scale (VAS) was used to evaluate the patients' subjective comfort, including thirst, hunger, anxiety, and nausea. The $0-100 \mathrm{~mm}$ scale represented discomfort levels of thirst, hunger, anxiety, and nausea, with 0 being no discomfort and 100 being maximum discomfort. Both groups fasted at $8 \mathrm{pm}$ before receiving surgery. Blood glucose and insulin were measured 3 hours before and immediately after surgery, and the IR index was calculated using the homeostatic model assessment (HOMA) formula: HOMA-IR = Fasting Plasma Glucose $(\mathrm{FPG}) \times$ Fasting Insulin (FINS)/22.5.

\section{Statistical analysis}

SPSS Statistics 23.0 (SPSS Inc., Chicago, IL, USA) was used to analyze the data. The mean \pm standard deviation 


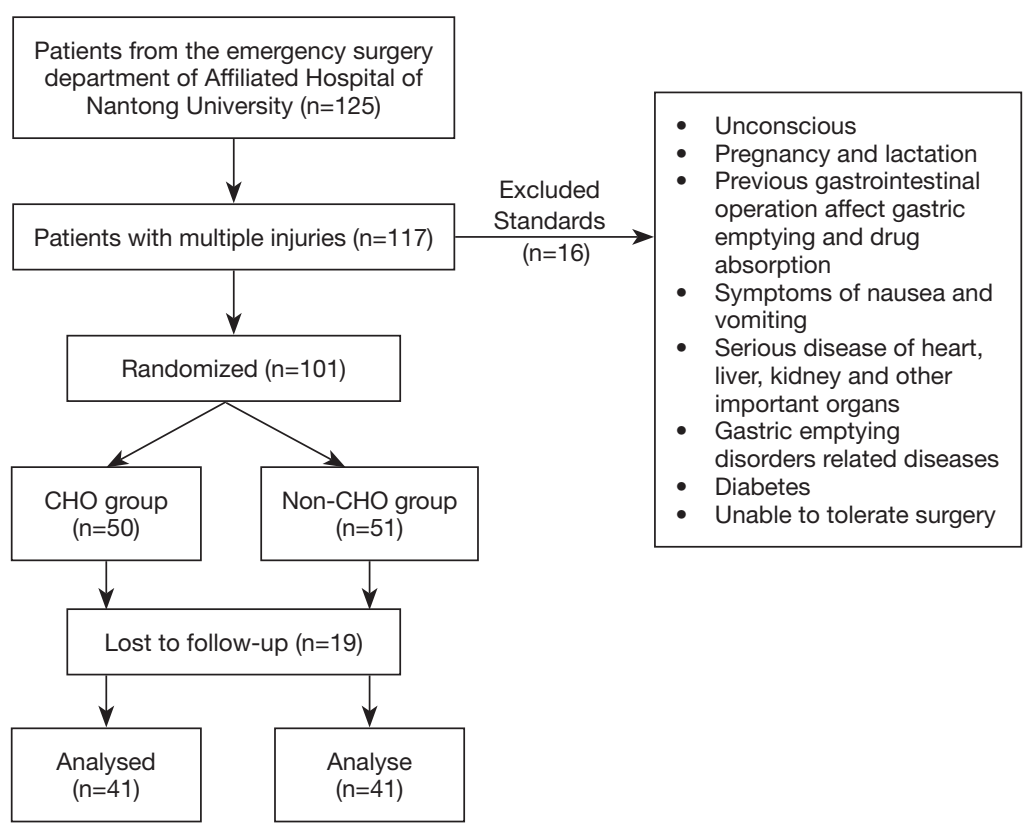

Figure 2 Flow chart.

Table 2 Patient characteristics

\begin{tabular}{|c|c|c|c|c|}
\hline Variables & $\mathrm{CHO}$ group $(n=41)$ & Non- $\mathrm{CHO}$ group $(n=41)$ & $\mathrm{t} / \chi^{2}$ & $P$ value \\
\hline Age (mean $\pm S D$ years) & $53.61 \pm 12.53$ & $53.71 \pm 13.58$ & -0.33 & 0.973 \\
\hline $\mathrm{BMI}\left(\right.$ mean $\left.\pm \mathrm{SD} \mathrm{kg} / \mathrm{m}^{2}\right)$ & $20.64 \pm 1.43$ & $20.31 \pm 1.30$ & 1.06 & 0.289 \\
\hline
\end{tabular}

Table 3 Surgical site of multiple injuries

\begin{tabular}{lccc}
\hline Variables & CHO group $(n=41)$ & Non-CHO group $(n=41)$ & Total $(n=82)$ \\
\hline Abdomen & 7 & 9 & 16 \\
Limbs & 23 & 19 & 42 \\
Pelvis & 11 & 13 & 24 \\
\hline
\end{tabular}

was used to describe data with normal distribution, and the median (quartile) was used to describe data with skewed distribution. Chi-square tests were used for normally distributed data, and $t$-tests were used to determine statistical differences between the two groups.

\section{Results}

\section{Patients}

A flow chart of participant selection is presented in Figure 2.
A total of 82 participants (39 males and 43 females) were ultimately recruited in this study. The individual characteristics of the patients are expressed in Tables 2,3. There were no significant differences between the two groups.

\section{Degree of comfort}

There was no significant difference between the two groups in subjective comfort levels as measured by thirst, hunger, 
Table 4 Comparison of patients' degree of comfort pre-surgery

\begin{tabular}{|c|c|c|c|c|}
\hline Variables & \multicolumn{2}{|c|}{$\mathrm{CHO}$ group } & \multicolumn{2}{|c|}{ Non-CHO group } \\
\hline Thirst & $21.43 \pm 9.23$ & $19.95 \pm 8.81$ & $21.48 \pm 8.47$ & $42.58 \pm 7.81^{\star \&}$ \\
\hline Hunger & $35.12 \pm 5.14$ & $15.63 \pm 4.85^{\star}$ & $35.70 \pm 5.42$ & $35.73 \pm 5.85^{\&}$ \\
\hline Anxiety & $51.12 \pm 11.02$ & $48.14 \pm 10.74^{*}$ & $50.97 \pm 10.97$ & $55.48 \pm 11.65^{\&}$ \\
\hline
\end{tabular}

*, intra-group comparison $\mathrm{P}<0.01$; ", intra-group comparison $\mathrm{P}<0.05$; ${ }^{\text {, }}$, inter-group comparison $\mathrm{P}<0.01$.

A

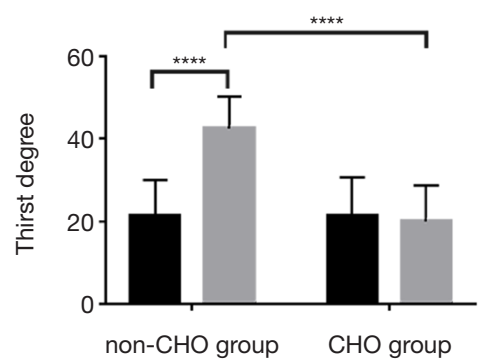

C

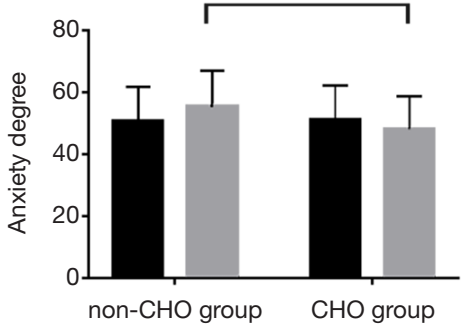

$3 \mathrm{~h}$ before surgery $\mathrm{B}$

$1 \mathrm{~h}$ before surgery

\section{B}
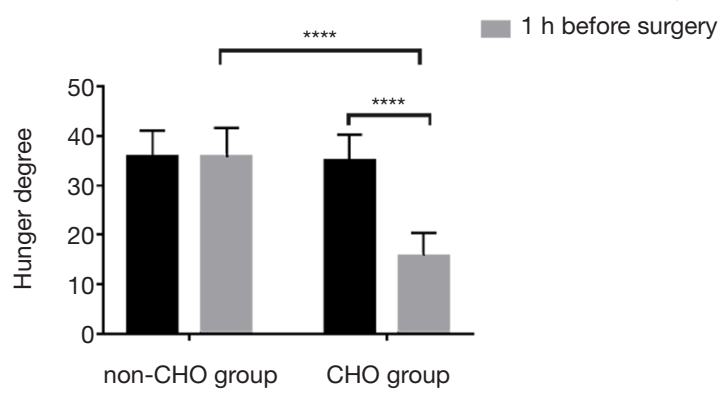

D

$3 \mathrm{~h}$ before surgery $1 \mathrm{~h}$ before surgery

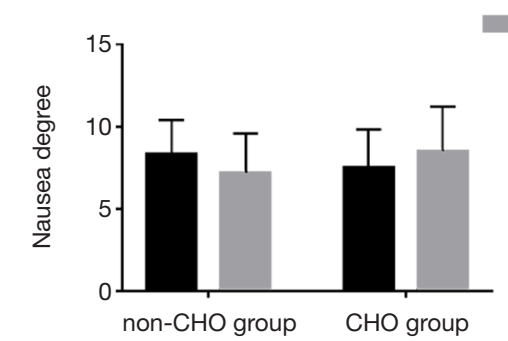

Figure 3 Comparison of degree of comfort. The results are shown as mean $\pm \mathrm{SD}$. Graphpad was used to calculate $\mathrm{P}$ values. * $\mathrm{P}<0.05$; ****, $\mathrm{P}<0.0001$.

anxiety, and nausea 3 hours before surgery $(\mathrm{P}>0.05)$ (Table 4). Within the CHO group, there was no difference between thirst, anxiety, and nausea 3 hours before surgery and 1 hour before surgery. Within the non-CHO group, hunger was significantly increased 1 hour before surgery compared with 3 hours before surgery. The subjective feelings, such as thirst, hunger, and anxiety, were significantly higher 1 hour before surgery in the non-CHO group compared with the CHO group (Figure 3).

\section{Blood glucose, insulin, and HOMA index}

Table 5 shows that there were no significant differences between the two groups in fasting blood glucose concentration, fasting insulin concentration, and IR index 3 hours before surgery. The blood glucose concentration, insulin concentration, and IR index of the two groups immediately following surgery were significantly higher than those prior to surgery. The levels of blood glucose, insulin concentration and IR index in CHO group were lower than those in non-CHO group immediately after the operation (Figure 4).

\section{Complications}

There was one case of restlessness, one case of dehiscence, 
Table 5 Blood glucose, insulin, and HOMA-IR

\begin{tabular}{|c|c|c|c|c|}
\hline Variables & \multicolumn{2}{|c|}{$\mathrm{CHO}$ group } & \multicolumn{2}{|c|}{ Non-CHO group } \\
\hline Plasma insulin concentration ( $\mathrm{mmol} / \mathrm{L})$ & $9.86 \pm 2.41$ & $38.42 \pm 8.24^{\star}$ & $9.84 \pm 2.33$ & $51.81 \pm 9.47^{\star \#}$ \\
\hline HOMA-IR & $2.57 \pm 0.78$ & $17.20 \pm 4.95^{\star}$ & $2.59 \pm 0.70$ & $29.00 \pm 7.87^{\star \#}$ \\
\hline
\end{tabular}

*, intra-group comparison $\mathrm{P}<0.01$; " , inter-group comparison $\mathrm{P}<0.01$. HOMA, homeostatic model assessment; IR, insulin resistance.
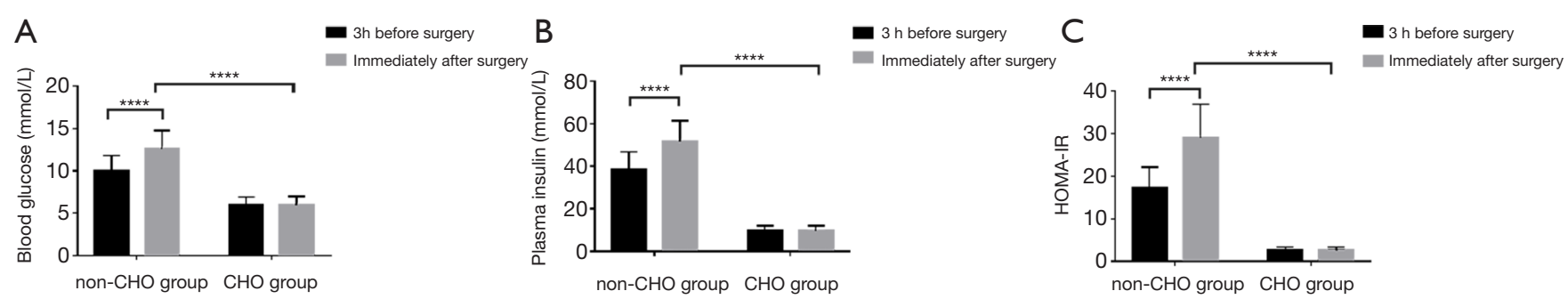

Figure 4 Comparison of blood glucose, insulin, and HOMA-IR. The results are shown as mean \pm SD. Graphpad was used to calculate P values. $^{* * * *}, \mathrm{P}<0.0001$. HOMA, homeostatic model assessment; IR, insulin resistance.

Table 6 Complications

\begin{tabular}{lcc}
\hline Variables & $\begin{array}{c}\text { CHO group } \\
\text { (cases) }\end{array}$ & $\begin{array}{c}\text { Non-CHO group } \\
\text { (cases) }\end{array}$ \\
\hline Vomit & 0 & 1 \\
Diarrhea & 0 & 2 \\
Restless & 1 & 0 \\
Incision infection & 0 & 1 \\
Incision dehiscence & 1 & 0 \\
Urinary tract infection & 1 & 0 \\
\hline
\end{tabular}

and one case of urinary tract infection post-surgery in the $\mathrm{CHO}$ group. In the non-CHO group, there was one case of vomiting, two cases of diarrhea, and one case of incision infection. There was no significant difference between the two groups in post-surgical complications (Table 6).

\section{Length of hospital stay}

Studies have shown that taking carbohydrates before surgery can reduce patients' hospital stay and promote rapid recovery after surgery (7). In our study, the length of hospital

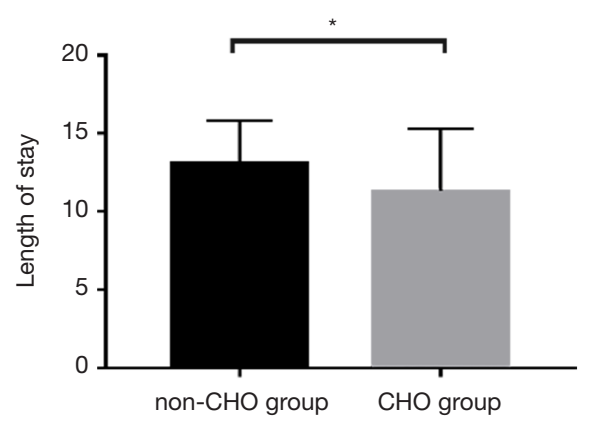

Figure 5 The length of hospital stay. The results are shown as mean \pm SD. Graphpad was used to calculate $\mathrm{P}$ values. ${ }^{*}, \mathrm{P}<0.05$.

stay was significantly reduced in the $\mathrm{CHO}$ group compared with the non-CHO group (CHO group: $11.29 \pm 2.77$; nonCHO group: $13.04 \pm 4.00 ; \mathrm{P}<0.05$ ) (Figure 5).

\section{Discussion}

Reducing postoperative IR plays a central role in the rapid surgical rehabilitation of patients. Much research has been done, to determine different methods of facilitating IR reduction after surgery. Among these methods, the application of preoperative carbohydrates stands out. 
Table 7 Components of oral solution

\begin{tabular}{lc}
\hline Components & Content $(\mathrm{g} / 100 \mathrm{~mL})$ \\
\hline Maltose & 0.7 \\
Polysaccharides & 10 \\
Glucose & 0.2 \\
Fructose & 1.3 \\
Sodium & 0.05 \\
Potassium & 0.122 \\
Chlorine & 0.006 \\
Calcium & 0.006 \\
Magnesium & 0.001 \\
\hline
\end{tabular}

Many studies have studied the physiological mechanism of preoperative carbohydrate use in reducing postoperative IR $(8,9)$. These mechanisms include reducing the level of stress hormones, changing the function of insulin receptors and changing the number of insulin receptors. However, most of these studies have focused on insulin resistance associated with gastrointestinal surgery, and patients with mild multiple injuries undergoing elective surgery have not been studied. The purpose of our study was to investigate whether preoperative carbohydrate administration had a similar effect on patients with multiple injuries as in patients undergoing gastrointestinal surgery. We found that preoperative administration of carbohydrate solution in patients with multiple injuries can reduce immediate insulin resistance after operation, shorten hospital stay, and thus contribute to rapid recovery. It also reduces the incidence of aspiration and improves the comfort of patients.

IR was present in the multiple injuries patients that participated in our study and was evaluated before and after the patients received surgery. However, hepatic glucose output cannot be completely inhibited by steady-state insulin concentrations in classic experiments, such as the glucose clamp test. This directly affects insulin sensitivity (10). HOMA-IR $($ FPG $\times$ FINS/22.5) has been used to evaluate the IR index in several studies on this subject and is determined by measuring fasting blood glucose and fasting insulin concentration. HOMA-IR was therefore used to determine the IR index in our study.

It (Table 7) shows the components of the carbohydrate solution given to the patient before operation, which, among other beneficial effects, avoids aspiration. Although osmotic pressure and viscosity were previously thought to be closely related, current studies have shown that gastric emptying time mainly depends on energy density. Electrolytes can also shorten the time of gastric emptying. Another important point is that carbohydrates are more palatable than glucose solutions $(11,12)$. Therefore, the carbohydrate solution used in our study consists not only of glucose, but also potassium, sodium, chlorine and other electrolytes. The only substance that provides energy is glucose, and there is no fat or protein in the solution.

Methods to reduce the incidence of aspiration were initially explored in fields such as obstetric anesthesia (13). As a result of this research, Mendelson proposed in the mid$20^{\text {th }}$ century that patients fast preoperatively from midnight of the day of the surgery; this has been routine since. Due to the relatively long fasting time (fasting including no eating and no drinking), individual differences between patients in gastric emptying can be ignored. Some studies have shown that the volume and acidity of gastric contents is not reduced after a long time of fasting and drinking, and this routine has gradually been proved to be one-sided in subsequent experiments (14-16).

The most common methods for evaluating the subjective comfort of patients are the VAS and the numerical rating scale (NRS). These measures are both easy to use in a clinical setting. The VAS requires patients to mark their level of comfort on a visual scale, which may be difficult for some elderly people $(17,18)$. NRS is used more frequently around the world, although some studies have shown that the correlation between VAS and NRS can be used to evaluate patients' subjective comfort more accurately (19). In our study, VAS was used to evaluate the subjective feelings of patients with multiple injuries including thirst, hunger, anxiety, and nausea. No significant difference was found between the $\mathrm{CHO}$ group and the non-CHO group 3 hours prior to surgery. However, one hour before operation, the subjective levels of thirst, hunger and anxiety in the $\mathrm{CHO}$ group were significantly lower than those in the non$\mathrm{CHO}$ group. Fasting from midnight can lead to water loss, lower blood sugar levels, depletion of extracellular fluid, and stimulation of hypothalamic osmotic receptors and thirst centers. In addition, fasting from midnight leads to less stimulation in the hypothalamic satiety center, while increased neuronal stimulation in the hypothalamic feeding center leads to thirst and hunger. The increase in the activity of the feeding center will reduce the activity of the satiety center, and this anxiety is related to the activity of the satiety center. Studies have found that taking carbohydrates before surgery can reduce the discharge frequency of satiety 
centers, thereby reducing anxiety (20).

The study showed that when anxious patients took 400 milliliters of oral carbohydrate solution three hours before surgery, stomach contents were emptied to safe residues in the same time as healthy people $(20,21)$. The carbohydrate solution used in this experiment was nearly isotonic; it did not contain fat, protein, or other substances that prolong gastric emptying time. In theory, this makes the solution relatively safe. Our study found that no patients who took oral carbohydrate solution prior to surgery experienced aspiration. Additionally, they experienced no increase in clinical complications such as infection, agitation, vomiting, or diarrhea.

The body's stress response is stimulated by stressors such as trauma, infection, blood loss, and hypothermia. Stress on metabolism is characterized by metabolic syndrome and inflammation. Metabolic syndrome is primarily a glucose metabolism disorder, but it includes other metabolic disorders, such as lipid metabolism disorder. The body produces greater amounts of stress hormones when under stress, which hinders sugar oxidation. At the same time, free fatty acids and amino acids antagonize glucose oxidation. A dominant characteristic of metabolic syndrome is IR. Type 2 diabetes mellitus is characterized by initial IR, followed by insufficient insulin secretion. Studies have shown that the development of type 2 diabetes is related to IR mediated by inflammatory factors, such as IL-1, IL-6, IL-8, IL-12, and TNF- $\alpha$ (22). Therefore, inflammation caused by stress is related to IR.

IR with hyperinsulinemia is a risk factor for cardiovascular diseases, such as hypertension, cardiomyopathy, coronary heart disease, arrhythmia, and heart failure by multiple pathways (23). Activation of the renin-angiotensinaldosterone system (RAAS) by IR leads to vascular smooth muscle proliferation, hypertrophy, and arteriosclerosis (24).

The purpose of our study was to investigate the effect of carbohydrates on immediate postoperative IR in patients with multiple injuries who underwent selective surgery. Before surgery there were no significant differences between the $\mathrm{CHO}$ group and the non-CHO group in fasting blood glucose, fasting insulin concentration, or IR index, although the non-CHO group exhibited higher values than the $\mathrm{CHO}$ group. Immediately after surgery, the IR index was lower in the CHO group than in the non$\mathrm{CHO}$ group. This suggests that preoperative fixed-time and quantitative carbohydrates can improve immediate IR in patients with multiple injuries. The specific mechanism was not investigated in our experiment.

Studies have shown that carbohydrates can be fermented and degraded by intestinal flora to produce short-chain fatty acids (SCFA), and butyrate can increase intestinal mucus production, the expression of zonulin, occludin, and tight junction proteins, as well as reduce intestinal permeability to maintain the intestinal barrier (25-27). Clostridium flexneri, Enterococcus, Bacteroides, and Escherichia coli levels in type 2 diabetes patients were higher than that present in healthy subjects. It is currently believed that the relative improvement of IR in the $\mathrm{CHO}$ group may be related to intestinal flora regulation by the carbohydrates administered prior to surgery, maintenance of the intestinal barrier, and reduction of the inflammatory response secondary to stressinduced intestinal flora displacement (28).

Studies have shown that ingesting carbohydrates prior to surgery can promote rapid recovery and reduce the length of hospital stay $(7,29,30)$. Inconsistent findings across studies may be a result of inconsistent treatments administered to patients and differences between these surgical patients.

\section{Conclusions}

The administration of $400 \mathrm{~mL}$ of carbohydrate solution before surgery improved patients' subjective comfort in terms of thirst, hunger, and anxiety, but there was no significant improvement in nausea. The incidence of post-surgical complications did not increase with carbohydrate administration. In addition to being safe and improving subjective comfort levels, carbohydrate administration before surgery also reduced immediate IR post-surgery, promoted rapid recovery in patients with multiple injuries, and reduced their length of hospital stay. Further exploration is required, however, to determine the mechanism by which IR is improved.

\section{Acknowledgments}

Funding: This study was supported by the National Natural Science Foundation of China (81801893) and the Nantong Clinical Medicine Research Center (HS2019005).

\section{Footnote}

Reporting Checklist: The authors have completed the CONSORT reporting checklist. Available at http://dx.doi. org/10.21037/apm-20-1424

Data Sharing Statement: Available at http://dx.doi. 
org/10.21037/apm-20-1424

Conflicts of Interest: All authors have completed the ICMJE uniform disclosure form (available at http://dx.doi. org/10.21037/apm-20-1424). The authors have no conflicts of interest to declare.

Etbical Statement: The authors are accountable for all aspects of the work in ensuring that questions related to the accuracy or integrity of any part of the work are appropriately investigated and resolved. The study was conducted in accordance with the Declaration of Helsinki (as revised in 2013), and has been approved by the Ethics Committee of the Affiliated Hospital of Nantong University (Approval number: 2019-L002), and all the subjects and their families signed the informed consent documents.

Open Access Statement: This is an Open Access article distributed in accordance with the Creative Commons Attribution-NonCommercial-NoDerivs 4.0 International License (CC BY-NC-ND 4.0), which permits the noncommercial replication and distribution of the article with the strict proviso that no changes or edits are made and the original work is properly cited (including links to both the formal publication through the relevant DOI and the license). See: https://creativecommons.org/licenses/by-nc-nd/4.0/.

\section{References}

1. Song $\mathrm{Y}, \mathrm{Ku} \mathrm{BJ}$, Cho J, et al. The prevalence of insulin refusal and psychological insulin resistance among Korean patients with type 2 diabetes mellitus. Ann Transl Med 2019;7:760.

2. Wang Q, Holmes MV, Davey Smith G, et al. Genetic Support for a Causal Role of Insulin Resistance on Circulating Branched-Chain Amino Acids and Inflammation. Diabetes Care 2017;40:1779-86.

3. Kehlet H, Wilmore DW. Evidence-based surgical care and the evolution of fast-track surgery. Ann Surg 2008;248:189-98.

4. Søreide E, Eriksson LI, Hirlekar G, et al. Pre-operative fasting guidelines: an update. Acta Anaesthesiol Scand 2005;49:1041-7.

5. Nygren J, Thorell A, Ljungqvist O, Preoperative oral carbohydrate nutrition: an update. Curr Opin Clin Nutr Metab Care 2001;4:255-9.

6. Onalan E, Andsoy II, Ersoy OF. The Effect of Preoperative Oral Carbohydrate Administration on Insulin
Resistance and Comfort Level in Patients Undergoing Surgery. J Perianesth Nurs 2019;34:539-50.

7. Amer MA, Smith MD, Herbison GP, et al. Network meta-analysis of the effect of preoperative carbohydrate loading on recovery after elective surgery. Br J Surg 2017;104:187-97.

8. Thorell A, Alston-Smith J, et al. The effect of preoperative carbohydrate loading on hormonal changes, hepatic glycogen, and glucoregulatory enzymes during abdominal surgery. Nutrition 1996;12:690-5.

9. Soop M, Nygren J, Myrenfors P, et al. Preoperative oral carbohydrate treatment attenuates immediate postoperative insulin resistance. Am J Physiol Endocrinol Metab 2001;280:E576-83.

10. Dunaif A, Segal KR, Futterweit W, et al. Profound Peripheral Insulin Resistance, Independent of Obesity, in Polycystic Ovary Syndrome. Diabetes 1989;38:1165-74.

11. Okabe T, Terashima H, Sakamoto A. Underlying principle of liquid gastric emptying. Br J Anaesth 2016;116:141.

12. Takii H, Takii Nagao $Y$, Kometani T, et al. Fluids containing a highly branched cyclicdextrin influence the gastric emptying rate. Int J Sports Med 2005;26:314-9.

13. Mendelson CL. The aspiration of stomach contents into the lungs during obstetric anesthesia. Am J Obstet Gynecol 1946;52:191-205.

14. Brady M, Kinn S, Stuart P. Preoperative fasting for adults to prevent perioperative complications. Cochrane Database Syst Rev 2003;(4):CD004423.

15. Hong JH, Kim HJ, Park KS, et al. Paradigm shift in the management of type B insulin resistance. Ann Transl Med 2018;6:S98.

16. Li L, Wang Z, Ying $X$, et al. Preoperative carbohydrate loading for elective surgery: a systematic review and metaanalysis. Surg Today 2012;42:613-24.

17. Briggs $M$, Closs JS. A descriptive study of the use of visual analogue scales and verbal rating scales for the assessment of post-operative pain in orthopedic patients. J Pain Symptom Manage 1999;18:438-46.

18. Jensen MP, Karoly P, Braver S. The measurement of clinical pain intensity: a comparison of six methods. Pain 1986;27:117-26.

19. Kamel HK, Phlavan M, Malekgoudarzi B, et al. Utilizing pain assessment scales increases the frequency of diagnosing pain among elderly nursing home residents. J Pain Symptom Manage 2001;21:450-5.

20. Nygren J, Thorell A, Jacobsson H, et al. Preoperative gastric emptying. Effects of anxiety and oral carbohydrate administration. Ann Surg 1995;222:728-34. 
21. Nygren J, Thorell A, Lagerkranser M, et al. Safety and patient well-being after preoperative oral intake of carbohydrate rich beverage. Clinical Nutrition 1996;15:30.

22. Xiong W, Meng XF, Zhang C. Inflammasome activation in podocytes: a new mechanism of glomerular diseases. Inflamm Res 2020;69:731-43.

23. Li YY, Lyu CH, Wu G, et al. Research progress on molecular mechanism of Dendrobium officinale and its active components to metabolic syndrome. Zhongguo Zhong Yao Za Zhi 2019;44:5102-8.

24. Ben-Dov IZ, Bursztyn M. Associations of Arterial Stiffness Indices With Measures of Insulin Resistance and Renal Sodium Reabsorption. Am J Hypertens 2019;32:810-2.

25. Barcelo A, Claustre J, Moro F, et al. Mucin secretion is modulated by luminal factors in the isolated vascularly perfused rat colon. Gut 2000;46:218-24.

26. Bordin M, D'Atri F, Guillemot L, Citi S. Histone

Cite this article as: Qi L, Wu Y, Shan L, Dong Y, Mao G, Liang G, Gong H, Xu C, Jiang H, Huang Z. A clinical study of preoperative carbohydrate administration to improve insulin resistance in patients with multiple injuries. Ann Palliat Med 2020;9(5):3278-3287. doi: 10.21037/apm-20-1424 deacetylase inhibitors up-regulate the expression of tight junction proteins. Mol Cancer Res 2004;2:692-701.

27. Peng L, He Z, Chen W, et al. Effects of butyrate on intestinal barrier function in a Caco-2 cell monolayer model of intestinal barrier. Pediatr Res 2007;61:37-41.

28. Saad MJ, Santos A, Prada PO. Linking Gut Microbiota and Inflammation to Obesity and Insulin Resistance. Physiology (Bethesda) 2016;31:283-93.

29. Ljungqvist O, Nygren J, Thorell A. Modulation of postoperative insulin resistance by pre-operative carbohydrate loading. Proc Nutr Soc 2002;61:329

30. Smith MD, McCall J, Plank L, et al. Preoperative carbohydrate treatment for enhancing recovery after elective surgery. Cochrane Database Syst Rev 2014;(8):CD009161.

(English Language Editors: B. Madden and J. Reynolds) 